\title{
Bowel Preparation for Colonoscopy: A Comparative Cost- Effective Analysis of Traditional Per OS Purgatory Prep Versus a Novel Method Using High-Volume Colonic Water Irrigation
}

\author{
Ananya Das ${ }^{1}$ Parth J Parekh², Pradeep Bekal ${ }^{3}$, William Stassen 4 , \\ Elizabeth Odstrcil ${ }^{5}$, Dawn Burleson ${ }^{6}$ and David A Johnson ${ }^{7 *}$ \\ ${ }^{1}$ Division of Gastroenterology, Arizona Center for Digestive Health, Gilbert, AZ United \\ States
}

2Department of Internal Medicine, Division of Gastroenterology and Hepatology,

\section{Research Article \\ Volume 2 Issue 4}

Received Date: December 16, 2017

Published Date: December 29, 2017

Carilion Clinic, Virginia Tech School of Medicine, Roanoke, VA United States

${ }^{3}$ Division of Gastroenterology, Ohio Gastroenterology and Liver Institute, Cincinnati, OH United States

${ }^{4}$ Division of Gastroenterology, Austin Gastroenterology, Austin, TX United States

${ }^{5}$ Division of Gastroenterology, Digestive Health Associates of Texas, Dallas, TX United States

6Department of Clinical and Regulatory Affairs, HyGIeaCare, Inc., Austin, TX United States

${ }^{7}$ Department of Internal Medicine, Chief of Gastroenterology, Eastern Virginia Medical School, Norfolk, VA United States

*Corresponding author: David A Johnson, MD MACG FASGE FACP, Department of Internal Medicine, Chief of Gastroenterology, Eastern VA Medical School Norfolk VA, 885 Kempsville rd suite 114 Digestive and Liver Diseases Norfolk VA 23502, United States, Tel: (757)466-0165; E-mail: dajevms@aol.com

\section{Abstract}

Objectives: Colonoscopy remains the cornerstone for colorectal screening as well as the diagnostic test of choice for positive screening tests or to further investigate the underlying etiology for various symptoms. The efficacy of colonoscopy hinges on an adequate preparation. Unfortunately, upwards of $1 / 4$ of colonoscopies performed have an inadequate prep. The economic burden, considering both indirect and direct costs, of an inadequate bowel preparation remains unknown. Recently a novel method of bowel preparation for colonoscopy has been made available using a FDAcleared high volume rectal irrigation device. The aim of this study is to perform a cost-effective analysis of high volume rectal water irrigation bowel preparation for colonoscopy and compare it to traditional preparations taking into account all direct and indirect costs. 


\section{Gastroenterology \& Hepatology International Journal}

Methods: A Markov cost-effectiveness model was developed comparing two bowel preparation regimens (split-dose PEG-ELS preparation vs. high volume rectal water irrigation) using a hypothetical cohort of 100,000 average-risk 50year-old United States(US) persons undergoing a screening colonoscopy. Clinical estimates and transitional probabilities simulating the natural history of colorectal cancer and performance statistics were derived. Direct costs were based on average reimbursement by the Centers for Medicare and Medicaid services. Indirect costs related to time spent by the patient an adult family member in preparing for colonoscopy was estimated by using the human capital method and available willingness to pay estimates. The average cost of travel was also included in the analysis.

Results: Use of novel high-volume rectal irrigation for colonoscopy preparation proved to be superior in cost (direct and indirect) when compared to traditional per OS purgatory preparation.

Conclusion: There is a significant economic burden associated with an inadequate bowel preparation. Use of high volume rectal irrigation for colon preparation is much more cost effective compared to traditional preparation when considering both direct and indirect costs over the long term period.

Keywords: Bowel Preparation; Colonoscopy; Hypothetical; Hypovolemia; Colonic

Abbreviations: CRC: Colorectal cancer; FIT: Fecal Immunochemical Testing; CTC: Computed Tomography Colonography; FDA: Food and Drug Administration; OTC: Over-The-Counter; ICER: Incremental Cost-Effectiveness Ratio; NNT: Number Needed to Treat; WTP: Willingness to Pay

\section{Background}

Colorectal cancer (CRC) is currently the second leading cause of cancer-related deaths amongst men and women in the United States (US). Colonoscopy remains the mainstay in CRC prevention by detecting and removing precancerous lesion [1]. In addition, colonoscopy is widely used for the diagnostic evaluation of other positive CRC screening tests (e.g. fecal immunochemical testing (FIT), FIT-fecal DNA, computed tomography colonography (CTC), etc.) or for symptoms (e.g. diarrhea, hematochezia, etc.). Irrespective, the success of colonoscopy hinges on the adequacy of the colon preparation. Current estimates are that 1 out of every 4 or 5 patients who present for colonoscopy have an inadequate bowel preparation. Patients and endoscopists are both negatively impacted by an inadequate bowel preparation. Patients undergoing a screening or surveillance colonoscopy are an increased risk for missed lesions, which are thought to account for greater than $80 \%$ of interval cancers [2,3]. In addition, an inadequate bowel preparation lower adenoma detection- and cecal intubation-rates, result in longer procedural times, place patients at an increased risk from electrocautery, and shorten screening or surveillance intervals for next colonoscopy [4].

Current expert consensus guidelines support the use of several different bowel oral purgatory preparations, with a split dose formulation now recommended as the standard of care [3,5-10]. Over the past decade, several new oral preparations have come to market [5]. Many of the newer formulations are being advertised as a "lowvolume solution" and while they do contain lower volumes of cathartic consumption, in reality the recommended additional fluid intake may approach the usual 4-liter volume for optimal preparation. While, these oral purgative bowel preparations are generally considered safe and well-tolerated, both patients and clinicians should be cognizant of potential adverse risks which include hypovolemia, nausea, vomiting, and electrolyte abnormalities (e.g. hypokalemia, hyponatremia, hypomagnesemia, and hypermagnesemia). In addition, split-dose prep is inconvenient as it causes a disruption in daily routines and work commitments [5].

Recently, a novel method of bowel preparation has been made available using a Food and Drug Administration (FDA)-cleared high-volume rectal irrigation device (HyGIeaCare, Inc., Austin, TX). This novel alternative to oral purgatory preparations allows for 


\section{Gastroenterology \& Hepatology International Journal}

adequate visualization of the colon while simultaneously lowering the barriers to entry for colonoscopy in patients who may not otherwise opt to pursue colonoscopy. Several studies, including a recently published randomized-control trial, have shown this method to be a safe alternative with a high percentage of adequate bowel preparation and increased patient satisfaction when compared to traditional oral purgatory preparations. However, this method of bowel preparation is not currently reimbursed by insurance carriers but it is commercially available in several cities in the United States (US) to consumers who are willing to pay out of pocket [11].

There is a tremendous financial burden associated with an inadequate preparation, with both direct and indirect costs incurred by both the patient and the endoscopist. A recent single-center study estimated that an annual savings of almost $£ 150,000$ by simply implementing a change in patient instructions and a pre-assessment of bowel preparations prescribed prior to colonoscopy. This study looked at direct cost benefit at an institutional level with the annual savings predominantly from a reduction in the number of repeat procedures required [12]. To date, there has not been any studies' evaluating the direct and indirect cost incurred by the physician and the patient as a result of a poor bowel preparation. The aim of our study is to perform a cost-effective analysis to compare this new modality of bowel preparation for colonoscopy to standard oral purgatory prep. Our hypothesis is that the high-volume rectal water irrigation method will be more cost-effective than standard prep, when considering all the direct and indirect costs of inadequate bowel preparations, i.e. repeat procedures, missed lesions, low adenoma detection rates, and loss of productivity.

\section{Methods}

\section{Data Collection}

Computer assisted recursive literature searches of MEDLINE, EMBASE, and Cochrane Databases (October 2001 to October 2016) were performed using predefined search criteria including the terms "colonoscopy" and "bowel preparation". Abstracts from major gastroenterology meetings were also searched for all relevant abstracts published from 2001 to 2016. Manual searches of the bibliography of selected publications were also performed. For estimates with respect to highvolume rectal irrigation, company data from HyGIeaCare, Inc. were used.

\section{Reference Case Definition}

The reference case will be an average 50-year old person undergoing an average-risk screening colonoscopy in the United States.

\section{Bowel Preparation Strategies}

Patients assigned to a standard bowel preparation strategy underwent bowel preparation using a 4 L, 2-day split dose of polyethylene glycol with electrolyte solution (PEG-ELS), as recommended by expert consensus guidelines [5]. In the baseline analysis, only a standard PEG-ELS preparation (GoLYTELY, Braintree Laboratories, Braintree, MA) was used, since it is the among most commonly used PEG-ELS for colonoscopy preparation. Sub-group analysis did include other FDA-approved commercial preparation regiments. These included sulfate-free PEG-ELS (NuLYTELY; Trilyte, Braintree Laboratories, Braintree, MA), low-volume PEG-ELS (Suprep or Suclear, Braintree Laboratories, Braintree, MA), and preparations that offer a combination of sodium picosulfate and magnesium citrate (Prepopik, Ferring Pharmaceutical, Parsippany, NJ). Over-the-counter (OTC) preparation regimens, e.g. low-volume PEG (Miralax, Merck, Boston, MA) and magnesium citrate, will not be evaluated in this model as they are not FDA approved for colonoscopy preparation. Additionally, the FDA has issued a black box warning for use of sodium phosphate (in tablet form) given the risk of kidney injury and electrolyte abnormalities, and thus will also not be included in this model.

Patients undergoing standard PEG-ELS split-dose preparation will ingest about half of the preparation (approximately 2L) the evening before their scheduled procedure and will wake up at 2 or $3 \mathrm{AM}$ the day of the procedure to ingest the remainder to complete the preparation. Experts recommend that the second dose of the split preparation should ideally begin 4-6 hours before the time of colonoscopy with completion of the second half at least 2 hours before start time [5]. Starting the second half of the split-dosed at 2 or 3 AM the will allow ample time for completion of their preparation and travel to the endoscopy center in order to have their procedure within the optimal window.

The alternative to conventional bowel preparation is use of a high-volume rectal irrigation device. These devices are situated at a preparation center typically in close proximity to their endoscopy center. The preparation center is staffed by a trained professional and supervised by a registered nurse. Patients will have the 


\section{Gastroenterology \& Hepatology International Journal}

ability to call the center prior to the preparation for education and counselling. The high-volume rectal irrigation system uses a slow stream of water drained by gravity, which is then infused via a soft nozzle into the rectum inducing natural colonic peristalsis. This allows the patient to effectively excrete feculent material while sitting on a sanitized basin, allowing for effective colon prep. The patient will be allowed to ingest clear liquids for up to 2 hours before their schedule procedure time, as recommended by the American Society of Anesthesiology [13].

\section{Decision Analysis Model}

In accordance with guidelines of the Panel on the CostEffectiveness in Health and Medicine, a model using a decision analysis software (TreeAge Pro 2009; TreeAge Software, Williamstown, MA) was constructed to evaluate two competing bowel preparation regimens (split dose PEG-ELS preparation vs. high-volume rectal water irrigation) using the hypothetical case as described above. A hybrid model of a linear decision tree terminating in a Markov model was also developed (Figure 1).

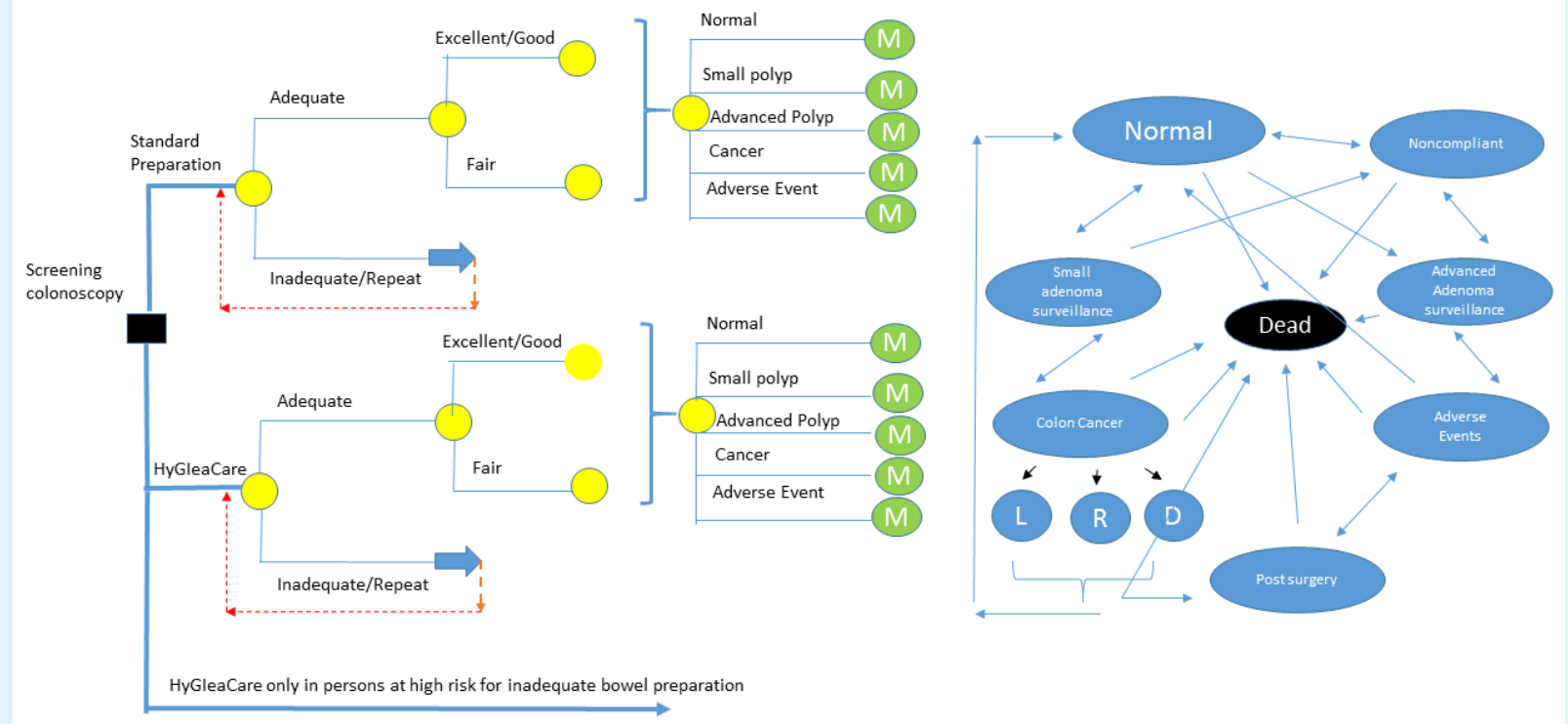

Figure 1: Decision tree and Markov models

The accompanying figure represents the basic structure of the decision analysis model. The tree starts with a black square decision node, the yellow circles are probability nodes, and the green circles are Markov nodes. On the right side, different Markov stages for each cycle of the model represents the natural history of an average risk person undergoing screening colonoscopy, with arrows pointing possible transition from one stage to another with stage-specific assigned transitional probabilities. Death is an absorbing stage.

$\mathrm{L}=$ Local; $\mathrm{R}=$ Regional; $\mathrm{D}=$ Distant

\section{Model Structure}

In the Markov model, the natural history of patients undergoing a screening colonoscopy will be modeled using various heath and disease states and compliance to CRC screening, each associated with a different set of costs and utilities (i.e. healthy without history of adenomatous polyps and compliant with CRC screening, noncompliant with CRC screenings, patients with low-risk adenomas, patients high-risk adenomas, patients who experience colonoscopy-related adverse events, patients with symptomatic and asymptomatic CRC (local, regional, and distant disease), and finally, death). At the end of each cycle in the model, which was set at 1 year, each patient was redistributed to different states depending on the estimated transitional probabilities among different 


\section{Gastroenterology \& Hepatology International Journal}

health states. Mortality rates were derived from agespecific mortality rates from the United States (US) as well as state specific mortality rates. Each state was allowed to transition to the next state or stay in the same state, however certain transitions were not permitted and death was considered an absorbing state [14,15].

Upon entry into the model, each patient underwent a screening colonoscopy. A certain portion of patients had an inadequate bowel preparation, characterized as having a Boston Bowel Preparation Score (BBPS) score <5. In such cases, these patients underwent a repeat colonoscopy within 1 year. Those patients who had an adequate preparation, their repeat screening or surveillance colonoscopy was determined in adherence with consensus guidelines $[8,16]$. All index procedures and subsequent colonoscopies were performed in an outpatient ambulatory surgery center setting with the assumption that all procedures in both strategies utilized anesthesia support and patients with adverse events required inpatient hospitalization with close observation or surgical intervention.

\section{Clinical Probabilities and Utilities}

A clinical probability, including transitional probabilities, between different health states and performance characteristics of patients in each cohort was derived from public information or from expert consensus opinion.

Quality adjusted life years (QALY) was estimated by adjusting the life expectancy of each health state by a weight or utility, which reflects patient preferences for that health state. Utility values were obtained from published information [17]. The loss of utility related to surgical resection as well as secondary to procedurerelated adverse events (observation and surgical intervention) were obtained through the 2014 Healthcare Cost and Utilization Project (HCUP). Multiple published cost-effectiveness analyses on CRC screening were utilized in order to determine loss of utility associated with colonoscopy preparation (e.g. loss of sleep time, diagnosis and management of CRC, CRC-related mortality, etc.) [18].

\section{Cost Estimates}

Costs, as opposed to charges, were considered in this analysis taking into account a third-party payer's perspective. Both direct and indirect costs were considered and all costs were adjusted to 2016 United States Dollars (USD) [19-22]. Direct costs were estimated based on the national average reimbursement allowed for each coded procedure by the Centers of Medicare and Medicaid Services during the fiscal year of 2015. Inpatient medical, surgical, and diagnostic services were assigned a current procedural terminology (CPT) or diagnosisrelated group (DRG) code to identify resource utilization. This data included costs related to diagnostic and therapeutic colonoscopy, primary resection (endoscopic vs. surgical), and the management of adverse events (conservative vs. surgical) $[23,24]$. Outpatient data was based on ambulatory payment classification and CPT codes. Cost of different bowel preparations were obtained from the American Society of Gastrointestinal Endoscope guidelines and the Red Book by Micromedex (Truven Health Analytics, Greenwood Village, C0) [13]. Cost estimates for high-volume rectal irrigation preparation were estimated from current out of pocket costs to patients utilizing this procedure in approved centers across the United States (US). Indirect costs (e.g. cost related to time spent preparing for colonoscopy) were estimated using both the human capital method and available willingness to pay (WTP), which included the average cost of travel to the rectal irrigation center and the endoscopy center [25-35]. Lastly, the cost of time spent by an accompanying adult (presumably a family member) during bowel preparation and for transporting to the patient to and from their procedure was estimated based on published information. Table 1 summarizes the cost variables (both estimated direct and indirect costs).

\begin{tabular}{|c|c|c|c|c|}
\hline Cost variables & Description & $\begin{array}{c}\text { Commercial } \\
\text { Insurance } \\
\text { Age }<65 \text { yrs }\end{array}$ & $\begin{array}{c}\text { Medicare } \\
\text { Age }>65 \text { yrs }\end{array}$ & References \\
\hline Cost of procedure & \multicolumn{2}{|c|}{ Cost of colonoscopy procedure + Cost of preparation + Indirect medical costs } \\
\hline Direct medical costs & & & & \\
\hline Cost of colonoscopy procedure & $\begin{array}{l}\text { Cost of colonoscopy procedure, which included } \\
\text { sedation costs and facility fees at an ambulatory }\end{array}$ & $\$ 1391$ & $\$ 722$ & $36-39$ \\
\hline
\end{tabular}

Ananya Das, et al. Bowel Preparation for Colonoscopy: A Comparative Cost-Effective Analysis of Traditional Per OS Purgatory Prep versus a Novel Method Using High-Volume Colonic Water Irrigation. Gastroenterol Hepatol Int J 2017, 2(4): 000132. 


\section{Gastroenterology \& Hepatology International Journal}

\begin{tabular}{|c|c|c|c|c|}
\hline & surgical center (ASC) & & & \\
\hline Cost of preparation & Cost of standard preparation with 4L PEG-ELS & $\$ 25$ & $\begin{array}{c}\$ 25 \\
(20-135)\end{array}$ & $36-39$ \\
\hline $\begin{array}{l}\text { Cost of novel high volume rectal } \\
\text { irrigation preparation }\end{array}$ & $\begin{array}{l}\text { Cost of preparation for colonoscopy at a } \\
\text { HyGIeaCare facility }\end{array}$ & $\begin{array}{c}\$ 250 \\
(150-1000)\end{array}$ & $\begin{array}{c}\$ 250 \\
(150-1000)\end{array}$ & $36-39$ \\
\hline $\begin{array}{l}\text { Cost of complication } \\
\text { (perforation) }\end{array}$ & $\begin{array}{l}\text { Total cost related to a procedure related } \\
\text { complication, in this case a perforation, } \\
\text { including a hospitalization if needed }\end{array}$ & $\$ 22,650$ & 16,778 & $36-39$ \\
\hline Cost of complication (bleeding) & $\begin{array}{l}\text { Total cost related to a procedure related } \\
\text { complication, in this case a bleeding, } \\
\text { including a hospitalization if needed }\end{array}$ & $\$ 8,321$ & $\$ 7,579$ & $36-39$ \\
\hline Cost of surgery & $\begin{array}{l}\text { Fost related to surgical resection of an advanced } \\
\text { polyp not amenable to endoscopic therapy }\end{array}$ & $\$ 21,500$ & $\$ 17,200$ & $36-39$ \\
\hline Costs related to colon cancer & Stage specific & & & \\
\hline $\begin{array}{l}\text { Cost of initial diagnosis and } \\
\text { management of CRC }\end{array}$ & Local stage & $\$ 32,912$ & $\$ 30,297$ & 36,39 \\
\hline $\begin{array}{l}\text { Cost of initial diagnosis and } \\
\text { management of CRC }\end{array}$ & Regional stage & $\$ 55,378$ & $\$ 50,970$ & 36,39 \\
\hline $\begin{array}{l}\text { Cost of initial diagnosis and } \\
\text { management of CRC }\end{array}$ & Distant stage & $\$ 72,314$ & $\$ 66,569$ & 36,39 \\
\hline $\begin{array}{l}\text { Cost of treatment per year for } \\
\text { maintenance therapy }\end{array}$ & Local stage & $\$ 3,535$ & $\$ 2,500$ & 36,39 \\
\hline $\begin{array}{l}\text { Cost of treatment per year for } \\
\text { maintenance therapy }\end{array}$ & Regional stage & $\$ 4,710$ & $\$ 3,212$ & 36,39 \\
\hline $\begin{array}{l}\text { Mortality cost of patients with } \\
\text { advanced colon cancer }\end{array}$ & Terminal stages & $\$ 112,316$ & $\$ 76,588$ & 36,39 \\
\hline Indirect costs & \multicolumn{4}{|c|}{$\begin{array}{l}\text { Indirect costs }=\text { Indirect medical cost }+ \text { Productivity losses for the patient and accompanying } \\
\text { person + Cost of travel }\end{array}$} \\
\hline & & $\begin{array}{l}\text { Standard } \\
\text { Preparation }\end{array}$ & $\begin{array}{l}\text { High Volume } \\
\text { Rectal Irrigation } \\
\text { Preparation }\end{array}$ & \\
\hline Loss of Productivity & \multicolumn{3}{|c|}{$\begin{array}{l}\text { Cost of loss of productivity related to colonoscopy for the patient. } \\
\text { Calculated by total lost time * hourly US average wage }(\$ 25.70)\end{array}$} & 31,40 \\
\hline Total Time Spent (Patient) & $\begin{array}{l}\text { Total time spent by patient related to } \\
\text { colonoscopy including preparation, and } \\
\text { recovery }\end{array}$ & 50 hours & 25 hours & $25,31-35$ \\
\hline $\begin{array}{l}\text { Total Time Spent } \\
\text { (Accompanying person) }\end{array}$ & $\begin{array}{l}\text { Total time spent by accompanying person } \\
\text { related to colonoscopy including } \\
\text { preparation, and recovery }\end{array}$ & 10 & 6 hours & $25,31-35$ \\
\hline
\end{tabular}




\section{Gastroenterology \& Hepatology International Journal}

\begin{tabular}{|c|c|c|c|c|}
\hline Cost of travel & \multicolumn{3}{|c|}{$\begin{array}{l}\text { Number of round trip miles } * \$ 0.19 \text { per mile based on } 2016 \text { rate IRS } \\
\text { reimbursement for travel costs incurred for medical transportation }\end{array}$} & 41 \\
\hline \multirow[b]{2}{*}{ Roundtrip miles } & Round trip miles from patient home to ASC & & \multirow[b]{2}{*}{20 miles } & \multirow[b]{2}{*}{34,35} \\
\hline & $\begin{array}{c}\text { and home to high-volume rectal irrigation } \\
\text { preparation center }\end{array}$ & 15 miles & & \\
\hline
\end{tabular}

Table 1: Cost variables that were input into the analysis

\begin{tabular}{|c|c|c|}
\hline Variable / Description & $\begin{array}{c}\text { Value } \\
\text { (Range) }\end{array}$ & Reference \\
\hline Dysutility related to colonoscopy & $\begin{array}{c}0.0055 \\
(0.0027-0.0082)\end{array}$ & 42,43 \\
\hline $\begin{array}{c}\text { Dysutility related to perforation complications of colonoscopy including hospital stay if } \\
\text { needed }\end{array}$ & $\begin{array}{c}0.0271 \\
(0.0082-0.0384)\end{array}$ & 42,43 \\
\hline $\begin{array}{c}\text { Dysutility related to bleeding complications of colonoscopy including hospital stay if } \\
\text { needed }\end{array}$ & $\begin{array}{c}0.01 \\
(0.0055-0.0192)\end{array}$ & 42,43 \\
\hline Dysutility related to surgical resection of an advanced polyp which not amenable to \\
endoscopic therapy & $\begin{array}{c}0.0178 \\
(0.0055-0.271)\end{array}$ & 42,43 \\
\hline Dysutility related to colon cancer: local stage & $\begin{array}{c}0.1 \\
(.05-0.2)\end{array}$ & $42-45$ \\
\hline Dysutility related to colon cancer: regional stage & $\begin{array}{c}0.2 \\
(0.1-0.3)\end{array}$ & $42-45$ \\
\hline Dysutility related to colon cancer: distant stage & $\begin{array}{c}0.24 \\
(0.15-.35)\end{array}$ & $42-45$ \\
\hline
\end{tabular}

Table 2: Utility variables that were input into the analysis

\section{Outcomes Compared and Statistical Methods}

The primary outcomes comparing the two strategies were incremental cost-effectiveness ratio (ICER) and net health benefit (NHB). ICER were calculated as the difference in costs divided by the difference in outcomes (life years) between the two competing strategies (ICER = [Cost Strategy I - Cost Strategy II]/[Effectiveness Strategy I - Effectiveness Strategy II]). The ICER is a measure of the added cost for each additional life years gained by Strategy II. The NHB of an alternative option was calculated using the formula: NHB = E - C / WTP, where E represents effectiveness, $C$ represents cost, and WTP is the willingness to pay (i.e. the decision maker's threshold ICER). Incremental NHB (INHB) will be calculated as the difference between the NHB of each strategy. NHB is often preferred to ICER as a measure of cost-effectiveness because of its direct interpretation as the average health gained per patient who under goes the alternative treatment adjusted for cost and WTP. Also, unlike ICER, the NHB is a monotonic function of both health and cost. Health policymakers should favor a strategy for which the NHB takes the greatest positive value in relation to values of WTP that seem reasonable with respect to known public policy [26]. For analysis of the results of the Monte Carlo analysis, relative risk with 95\% confidence intervals and number needed to treat (NNT) were calculated.

\section{Sensitivity Analysis}

The robustness of the model was tested by performing a sensitivity analysis using clinical probabilities and cost estimates. Univariate and multivariate sensitivity analysis was performed using clinical variables, cost, and quality of life (QOL) estimates. In a hypothetical cohort of 100,000 patients undergoing a screening colonoscopy, a second-order Monte Carlo simulation was performed to calculate probabilistic sensitivity analysis. Monte Carlo 


\section{Gastroenterology \& Hepatology International Journal}

simulation recalculates a model multiple and incorporates uncertainties into an analysis in keeping with real-life situations [27]. In this method, sampling probability values from probability distributions of variables (rather than from a single range defined by upper and lower bounds) places greater weight on likely combination of parameter values and simulation results quantify the total impact of uncertainty on the model in terms of the confidence that can be placed in the analysis results. Threshold analyses were performed to understand the impact of the variability of key clinical and cost estimates and also the various threshold points, if any, where one strategy dominates the competing strategy.

\section{Assumptions}

The following assumptions were made in this model primarily because of limited or lack of published data:

1. The decision models were built on the assumption that CRC screening would negate cancer-related loss in life years and that patients would fully benefit from the restored life expectancy of an average population without CRC. The models did not consider the presence of other competing medical risks in some of the subjects undergoing screening.
2. The baseline model considered only average-risk patients undergoing outpatient screening colonoscopy.

3. The model assumes that once a patient underwent a colonoscopy with a particular regimen that the same regimen will be used for subsequent colonoscopies.

4. The model only took into account colonoscopy for CRC screening. No other methods of CRC screening were evaluated in this model.

5. The model assumes that one adult family member (typically a spouse) was involved in assisting the patient with preparation for colonoscopy and for providing transportation to and from the rectal irrigation center (if needed) and then to the endoscopy center.

6. Recovery time after the procedure, related cost, and disutility after an uncomplicated procedure was assumed to be similar under both strategies.

\section{Results}

In a baseline analysis, HyGIeaCare preparation proved to be less expensive when compared to traditional per os preparation ( $\$ 15,538$ vs $\$ 18,847$, respectively) with a higher QALY (13.700 vs 13.036, respectively) (Tables 3 \& 4).

\begin{tabular}{|c|c|c|}
\hline Variable / Description & $\begin{array}{l}\text { Value } \\
\text { (Range) }\end{array}$ & Reference \\
\hline Age at entry into the model (years) & $\begin{array}{c}50 \\
(50-80)\end{array}$ & Assumption \\
\hline Probability of adequate cleansing with standard preparation & $\begin{array}{c}0.85 \\
(0.75-0.90)\end{array}$ & $5,10,46$ \\
\hline $\begin{array}{l}\text { Probability of excellent to good cleansing with standard preparation } \\
\text { b. A. Atter initial inadequate preparation }\end{array}$ & $\begin{array}{l}\text { a. } 0.6(0.4-0.7) \\
\text { b. } 0.5(0.35-0.7)\end{array}$ & $5,10,46-48$ \\
\hline Probability of adequate cleansing with HyGIeaCare based preparation & $0.97(0.85-0.98)$ & 11,49 \\
\hline $\begin{array}{l}\text { Probability of excellent to good cleansing with HyGleaCare based preparation } \\
\qquad \begin{array}{c}\text { b. a. Atter initial inadequate preparation } \\
\text { b. Anane }\end{array}\end{array}$ & $\begin{array}{l}\text { a. } 0.8(0.7-0.85) \\
\text { b. } 0.7(0.6-0.8)\end{array}$ & 11,49 \\
\hline Probability of low-risk adenoma at screening colonoscopy (age dependent) & $\begin{array}{l}0.15 \text { (if }<65 \text { yrs) } \\
0.17 \text { (if }>65 \text { yrs) } \\
\quad(0.1-0.25)\end{array}$ & 50,51 \\
\hline Probability of high-risk adenoma at screening colonoscopy (age dependent) & $\begin{array}{l}0.038 \text { (if }<65 \text { yrs }) \\
(0.02-0.05) \\
0.082 \text { (if }>65 \text { yrs }) \\
(0.05-0.1)\end{array}$ & 50,51 \\
\hline
\end{tabular}

Ananya Das, et al. Bowel Preparation for Colonoscopy: A Comparative Cost-Effective Analysis of Traditional Per OS Purgatory Prep versus a Novel Method Using High-Volume 


\section{Gastroenterology \& Hepatology International Journal}

\begin{tabular}{|c|c|c|}
\hline Probability of high-risk adenoma amenable to endoscopic therapy & $\begin{array}{c}0.91 \\
(0.87-0.95)\end{array}$ & 43 \\
\hline $\begin{array}{c}\begin{array}{c}\text { Probability of asymptomatic colorectal cancer at screening colonoscopy (age } \\
\text { dependent) }\end{array}\end{array}$ & $\begin{array}{c}0.001 \\
(0.0005-0.002) \\
(\text { if }<65 \text { yrs) } \\
0 . .007 \\
(0.002-0.01) \\
\text { (if }<65 \text { yrs) }\end{array}$ & 50,51 \\
\hline $\begin{array}{l}\text { Probability of false negative results for colonoscopy for low-risk adenoma } \\
\begin{array}{c}\text { a. } \text { Excellent/good preparation } \\
\text { b. } \quad \text { Fair preparation }\end{array}\end{array}$ & $\begin{array}{l}\text { a. } 0.01 \\
(0.03-0.15) \\
\quad \text { b. } 0.15 \\
(0.1-0.2)\end{array}$ & $50-53$ \\
\hline $\begin{array}{l}\text { Probability of false negative results for colonoscopy for high-risk adenoma } \\
\begin{array}{ll}\text { a. } & \text { Excellent/good preparation } \\
& \text { b. } \quad \text { Fair preparation }\end{array}\end{array}$ & $\begin{array}{l}\text { a. } 0.05 \\
\quad(0.01-0.1) \\
\text { b. } 0.10(0.05-0.15)\end{array}$ & $50-53$ \\
\hline $\begin{array}{l}\text { Probability of false negative results for colonoscopy for colorectal cancer } \\
\begin{array}{ll}\text { a. } & \text { Excellent/good preparation } \\
& \text { b. } \quad \text { Fair preparation }\end{array}\end{array}$ & $\begin{array}{l}\text { a. } \quad 0.005 \\
(.0001-.001) \\
\text { b. } 0.05 \\
(0.01-0.1)\end{array}$ & $50-53$ \\
\hline Probability of major hemorrhage related to screening colonoscopy & $0.008(0.003-0.01)$ & $51,54,55$ \\
\hline Probability of perforation related to screening colonoscopy & $0.004(0.001-0.007)$ & $51,54,55$ \\
\hline $\begin{array}{c}\begin{array}{c}\text { Probability of annual transition rate from normal to low-risk adenoma (age } \\
\text { dependent) }\end{array}\end{array}$ & $0.02(0.01-0.03)$ & $51,56-60$ \\
\hline $\begin{array}{c}\begin{array}{c}\text { Probability of annual transition rate from low-risk adenoma to high-risk } \\
\text { adenoma }\end{array}\end{array}$ & $0.019(0.01-0.03)$ & $51,56-60$ \\
\hline Probability of annual transition rate from high-risk adenoma to local cancer (\%) & $0.048(0.03-0.07)$ & $51,56-60$ \\
\hline $\begin{array}{l}\text { Probability of annual transition rate to cancer without polypoid precursor (age } \\
\text { specific) }\end{array}$ & $0.00006-0.00086$ & $51,56-60$ \\
\hline Probability of annual transition rate from local CRC to regional CRC & $0.3(0.1-0.5)$ & 61 \\
\hline Annual transition rate from regional CRC to distant CRC & $0.4(0.2-0.6)$ & 61 \\
\hline Annual mortality rate from treated localized cancer (first 5 years) & $0.014(0.01-0.22)$ & $51,62,63$ \\
\hline Annual mortality rate from treated regional cancer (first 5 years) & $0.1(0.05-0.15)$ & 51 \\
\hline Annual mortality rate from treated distant cancer (first 5 years) & $0.18(.1-0.25)$ & $51,62,63$ \\
\hline $\begin{array}{l}\text { Probability of stages of colorectal cancer at diagnosis } \\
\begin{aligned} & \text { a. } \text { With prior screening } \\
& \text { Local stage } \\
& \text { Regional stage } \\
& \text { Distant stage } \\
& \text { b. } \quad \text { Without prior screening }\end{aligned}\end{array}$ & $\begin{array}{l}\text { a. } \\
0.43(0.4-0.5) \\
0.49(0.4-0.6) \\
0.08(0-0.9) \\
\text { b. }\end{array}$ & $51,64-66$ \\
\hline
\end{tabular}




\begin{tabular}{|c|c|c|}
\hline $\begin{array}{c}\text { Local stage } \\
\text { Regional stage } \\
\text { Distant stage }\end{array}$ & $\begin{array}{c}0.15(0.12-0.25) \\
0.63(0.5-0.7) \\
0.22(0.18-0.25)\end{array}$ & \\
\hline $\begin{array}{c}\text { Probability of non-compliance with colorectal screening after initial } \\
\text { colonoscopy based screening }\end{array}$ & $0.35(0.2-0.7)$ & $51,64-66$ \\
\hline $\begin{array}{c}\text { Probability of noncompliance with recommended follow up colonoscopy within } \\
\text { 1 year after initial colonoscopy with inadequate preparation }\end{array}$ & $0.1(0-0.15)$ & $\begin{array}{c}\text { Expert } \\
\text { opinion }\end{array}$ \\
\hline Annual mortality (age dependent) & US Life Table (2011) & 67 \\
\hline
\end{tabular}

Table 3: Variables that were input into the analysis

\begin{tabular}{|c|c|c|c|}
\hline \multicolumn{4}{|c|}{ Societal perspective: Only direct costs considered } \\
\hline Strategy & Cost $(\$)$ & Effectiveness (QALY) & ICER \\
\hline Standard & $\$ 15,464$ & 13.036 & Dominated \\
\hline HyGleaCare & $\$ 13,951$ & 13.700 & - \\
\hline \multicolumn{4}{|c|}{ Patient perspective: Only indirect costs considered } \\
\hline (Out of pocket costs for preparation, cost of travel, and cost related to loss of productivity) \\
\hline Standard & $\$ 3,437$ & 13.036 & Dominated \\
\hline HyGleaCare & $\$ 2,083$ & 13.700 & - \\
\hline
\end{tabular}

Table 4: Baseline analysis

The model was sensitive to two variables specific to the HyGleaCare-based strategy. The first was the cost of the preparation. A 1-way sensitivity found that the threshold cost for a HyGIeaCare-based preparation was $\$ 975$, where any further increase in cost was no longer cost effective (Figure 2).

The second variable was the cost effectiveness and likelihood of achieving an adequate preparation using the HyGleaCare-based preparation. A 2-way sensitivity analysis using cost of HyGleaCare preparation and probability of adequate cleansing using the variables input the model. 2-way sensitivity analysis demonstrated HyGleaCare preparation to be highly cost-effective, particularly at its current market price of $\$ 250$ (Figure 3). The sensitivity analysis also demonstrated that despite the tendency of specific variables to impact the net ICER (i.e. age of screening colonoscopy, probability of adequate cleansing with standard preparation, and noncompliance with initial and subsequent colonoscopy) the overall conclusion of the model remained unchanged (Figure 4).

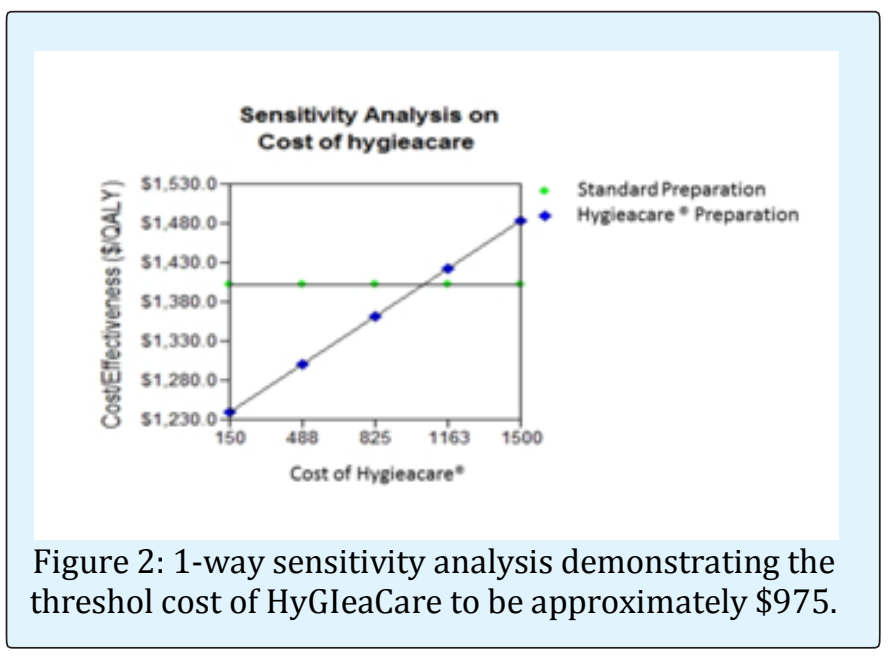




\section{Gastroenterology \& Hepatology International Journal}

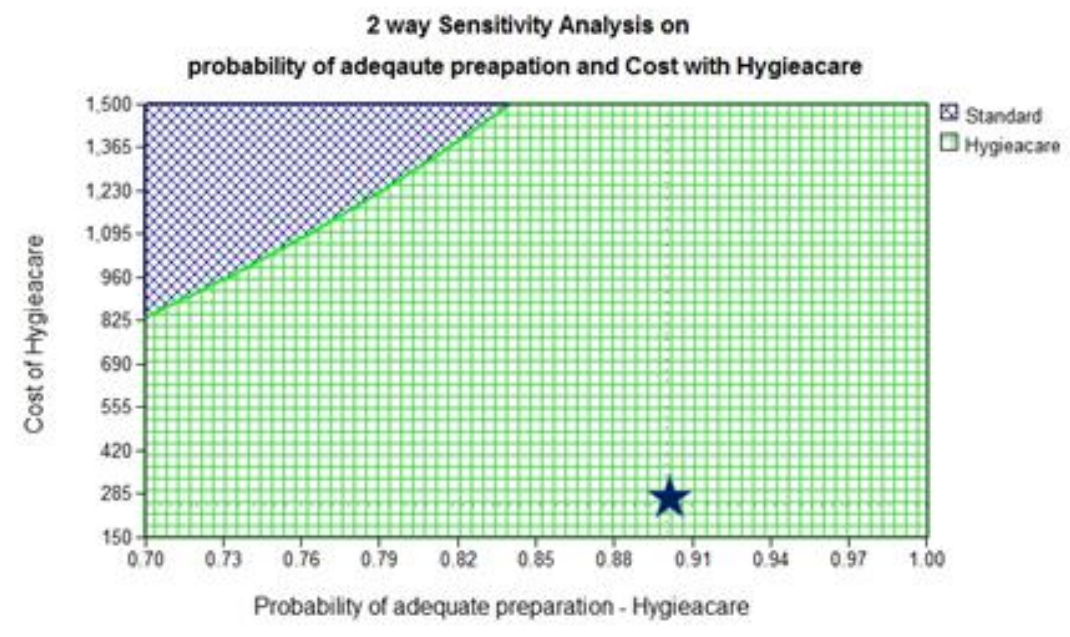

Figure 3: 2-way sensitivity analysis demonstrating the HyGleaCare to be highly cost effective. Legend: The blue star marks the current market price of $\$ 250$.

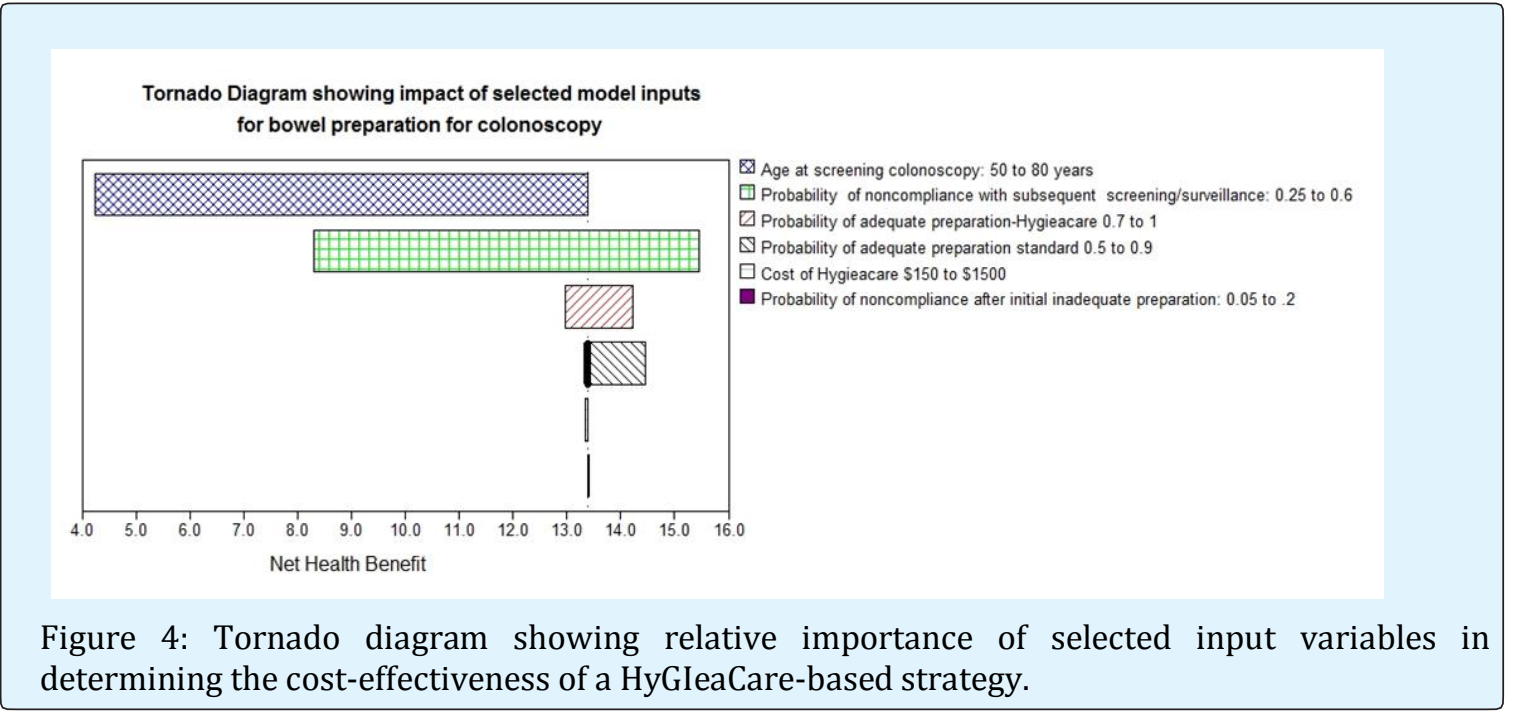

A Monte Carlo simulation trial, which investigated the life-time of the studied cohort, found a relative risk reduction of colon cancer using the HyGIeaCare-based strategy to be $0.58(95 \%$ CI $0.54-0.61 ; \mathrm{p}<0.001)$ with a NNT of 85 (95\% CI 77-96). The total life-time cost saving for the totality of the studied cohort was $\$ 150,064,650$. The simulation trials also demonstrated the estimated net health benefit (NHB) to be higher with the HyGleaCarebased preparation at a wide range of willingness to pay (WTP) (Figure 5). In a probabilistic sensitivity analysis of 10,000 simulation trials, HyGleaCare preparation remained the preferred strategy, with a significantly higher number of trials yielding higher QALY with a lower cost when compared to standard preparation (Figure 6). 


\section{Gastroenterology \& Hepatology International Journal}

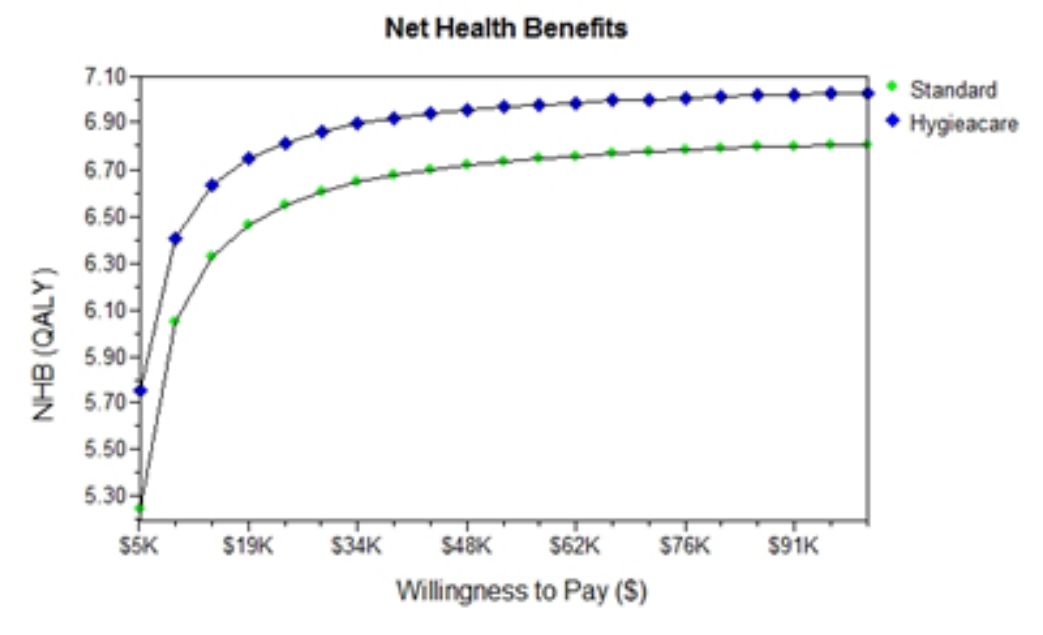

Figure 5: Second order Monte Carlo trials, simulating a randomized-control trial, which demonstrates the NHB to be higher with a HyGleaCare-based strategy at a wide range of WTP.

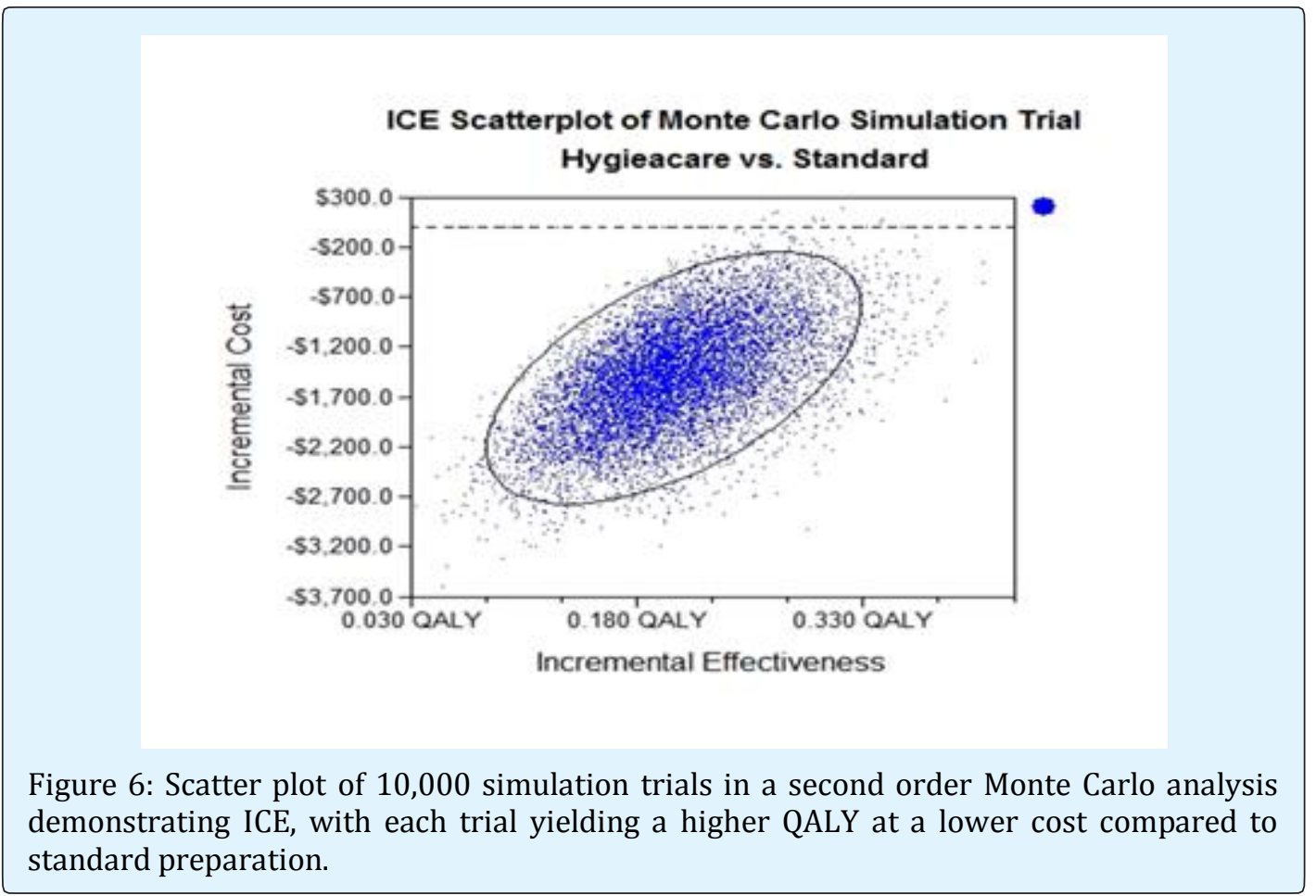

\section{Discussion}

Inadequate bowel preparations limit the overall utility and impact of colonoscopy, whether it be screening or diagnostic. Recently a high-volume rectally administered irrigation based bowel preparation has become available as an alternative to traditional per os purgatory preparations. Studies have demonstrated its superiority in terms of tolerability and efficacy. Currently, however, this method of preparation is not being reimbursed by 


\section{Gastroenterology \& Hepatology International Journal}

insurance carriers. This economic analysis demonstrates that this novel method of bowel preparation is cheaper as well as more effective compared to standard split-dose PEG-ELS in patients undergoing screening colonoscopy.

To date, there has not been any studies published analyzing the cost-effectiveness of different bowel preparations. Recent publications, however, have focused on the economic impact of inadequate bowel preparations. These studies reiterate the importance of an adequate bowel preparation for the cost-effectiveness of a screening colonoscopy [12,36-38].

In the current economic analysis, we performed the baseline analysis by taking into account both the direct and indirect costs related to screening colonoscopy. Limited published economic analyses of colorectal cancer screening typically consider only direct costs, despite the recommendations of the Consensus Panel on Costeffectiveness in Health and Medicine to include both direct and indirect costs. The indirect costs (i.e. loss of productivity by both the patient and the family, and the cost of travel-related to the procedure) unfortunately are often overlooked, despite recent publications emphasizing its importance. The human capital method is the recommended method of measuring the indirect costs of lost time and productivity related to the preparation and recovery from the procedure $[25,31,32,39,40]$. The national hourly average was then multiplied by the estimated loss of time in order to determine indirect cost $[25,31,40]$. For travel-related costs, we used the reported average amount of travel required for getting a colonoscopy and allowable tax deductions for travel costs incurred for medical transportation.

Even whilst removing indirect costs and analyzing the direct cost of both standard preparation and the HyGIeaCare-based preparation, HyGIeaCare preparation was significantly more cost effective. This primarily owns to the lower rate of inadequate preparation with traditional preparations requiring repeat intervention.

There are two limitations of this analysis. First, the assumptions used favored traditional preparations to a certain extent. For example, we assumed that the complication rate and level of compliance to be similar in both strategies despite data suggesting that a rectal infusion based strategy may be more palatable for patients and is also likely to reduce the complications associated with a poor preparation. A second limitation is our assumption that an adult family member (typically a spouse) will be involved in assisting the patient with preparation and for providing transportation, which incurs time and productivity loss. This assumption is based on a few studies and thus extrapolation data may not necessarily be generalizable. Third, we used the recommended human capital method in order to estimate indirect cost. One could argue that the loss of time and productivity during preparation is intermittent as the patient may be able to multi-task during that period of time and thus may be partially productive. A counterpoint would be that this analysis does not take into account the discomfort and loss of quality of life related to the preparation, e.g. sleep disturbance.

\section{Conclusion}

Inadequate bowel preparations are the leading cause of failed colonoscopy, which results in delayed diagnosis, repeat procedures, and any accelerated inherent risk associated with procedures. There have been several changes made to traditional preparations in order to overcome its pitfalls (e.g. palatability, lower volumes, etc.) over the past several years, however approximately up to a $1 / 4$ of patients undergoing a colonoscopy will have an inadequate preparation. Beyond the immediate disadvantages of an inadequate exam (e.g. delay in diagnosis, unnecessary repeat procedures, and an increase risk of procedure-related complications) the direct and indirect costs to both the patient and the family are evident and considerable. A novel high volume rectally administered irrigation preparation overcomes the pitfalls of traditional peroral purgatory preparations, namely a higher percentage of predictably adequate colon preps that is a much more cost effective prep compared to traditional preparations.

Conflicts of Interest: Parth J Parekh, MD and David A Johnson, MD MACG FASGE FACP are consultants for HyGIeaCare, Inc. Dawn Burleson; RN MBA is an employee of HyGIeaCare, Inc. Research funded by HyGIeaCare, Inc.

\section{References}

1. Siegel R, Naishadham D, Jemal A (2012) Cancer statistics, 2012. CA Cancer J Clin 62(1): 10-29.

2. Froehlich F, Wietlisbach V, Gonvers JJ, Burnand B, Vader JP (2005) Impact of colonic cleansing on quality and diagnostic yield of colonoscopy: the European Panel of Appropriateness of Gastrointestinal Endoscopy European multicenter study. Gastrointest Endosc 61(3): 378-384. 


\section{Gastroenterology \& Hepatology International Journal}

3. Harewood GC, Sharma VK, De garmo P (2003) Impact of colonoscopy preparation quality on detection of suspected colonic neoplasia. Gastrointest Endosc 58(1): 76-79.

4. Le clercq CM, Bouwens MW, Rondagh EJ, Bakker CM, Keulen ET, et al. (2014) Postcolonoscopy colorectal cancers are preventable: a population-based study. Gut 63(6): 957-963.

5. Johnson DA, Barkun AN, Cohen LB, Dominitz JA, Kaltenbach T, et al. (2014) Optimizing adequacy of bowel cleansing for colonoscopy: recommendations from the US multi-society task force on colorectal cancer. Gastroenterology 147(4): 903-924.

6. Clark BT, Protiva P, Nagar A, Imaeda A, Ciarleglio MM, et al. (2016) Quantification of Adequate Bowel Preparation for Screening or Surveillance Colonoscopy in Men. Gastroenterology 150(2): 396405.

7. Bond JH, Levitt MD (1975) Factors affecting the concentration of combustible gases in the colon during colonoscopy. Gastroenterology 68(6): 14451448.

8. Rex DK, Boland CR, Dominitz JA, Giardiello FM, Johnson DA, et al. (2017) Colorectal Cancer Screening: Recommendations for Physicians and Patients from the U.S. Multi-Society Task Force on Colorectal Cancer. Am J Gastroenterol 112(7): 1016-1030.

9. Johnson DA, Barkun AN, Cohen LB, Dominitz JA, Kaltenbach T, et al. (2014) Optimizing adequacy of bowel cleansing for colonoscopy: recommendations from the US Multi-Society Task Force on Colorectal Cancer. Am J Gastroenterol 109(10): 1528-1545.

10. Saltzman JR, Cash BD, Pasha SF, Early DS, Muthusamy VR, et al. (2015) Bowel preparation before colonoscopy. Gastrointest Endosc 81(4): 781-794.

11. Sportes A, Delvaux, Huppertz, Hernandez, Gay G (2016) Randomized trial comparing high volume rectal water irrigation with standard $4 \mathrm{~L}$ Split-Dose PEG preparation before colonoscopy. J Gastroenterol \& Dig Dis 1(1): 3.

12. Gardezi SA, Tibbatts C (2017) Improving bowel preparation for colonoscopy in a cost effective manner. BMJ Qual Improv Rep 6(1): u204560.w5376.
13. American Society of Anesthesiologists Committee (2017) Practice Guidelines for Preoperative Fasting and the Use of Pharmacologic Agents to Reduce the Risk of Pulmonary Aspiration: Application to Healthy Patients Undergoing Elective Procedures: An Updated Report by the American Society of Anesthesiologists Task Force on Preoperative Fasting and the Use of Pharmacologic Agents to Reduce the Risk of Pulmonary Aspiration. Anesthesiology 126(3): 376393.

14. Paulden M, Omahony JF, Mccabe C (2017) Discounting the Recommendations of the Second Panel on Cost-Effectiveness in Health and Medicine. Pharmacoeconomics 35(1): 5-13.

15. Sonnenberg FA, Beck JR (1993) Markov models in medical decision making: A practical guide. Med Decis Making 13(4): 322-338.

16. Kahi CJ, Boland CR, Dominitz JA, Giardiello FM4, Johnson DA, et al. (2016) Colonoscopy Surveillance After Colorectal Cancer Resection: Recommendations of the US Multi-Society Task Force on Colorectal Cancer. Gastroenterology 150(3): 758-768.

17. Weinstein MC, Siegel JE, Gold MR, Kamlet MS, Russell LB (1996) Recommendations of the Panel on Costeffectiveness in Health and Medicine. JAMA 276(15): 1253-1258.

18. Fox JP, Burkardt DD, Ranasinghe I, Gross CP (2014) Hospital-based acute care after outpatient colonoscopy: implications for quality measurement in the ambulatory setting. Med Care 52(9): 801-808.

19. Lieberman D (2001) Cost-effectiveness of colonoscopy in screening for colorectal cancer; costeffectiveness of screening colorectal cancer in the general population. Gastrointest Endosc 54(4): 537538.

20. Sonnenberg A, Delcò F, Inadomi JM (2000) Costeffectiveness of colonoscopy in screening for colorectal cancer. Ann Intern Med 133(8): 573-584.

21. Sonnenberg A, Delcò F, (2002) Cost-effectiveness of a single colonoscopy in screening for colorectal cancer. Arch Intern Med 162(2): 163-168.

22. Pignone M, Saha S, Hoerger T, Mandelblatt J (2002) Cost-effectiveness analyses of colorectal cancer 


\section{Gastroenterology \& Hepatology International Journal}

screening: a systematic review for the U.S. Preventive Services Task Force. Ann Intern Med 137(2): 96-104.

23. HCUPnet Healthcare cost and utilization project. Rockville (MD): Agency for Healthcare Research and Quality.

24. Proposed CY2005 hospital outpatient prospective payment system: addendum A.

25. Jonas DE, Russell LB, Chou J, Pignone M (2010) Willingness-to-pay to avoid the time spent and discomfort associated with screening colonoscopy. Health Econ 19(10): 1193-1211.

26. Heitjan DF, Fiellers (2000) method and net health benefits. Health Econ 9(4): 327-335.

27. Doubilet P, Begg CB, Weinstein MC, Braun P, Mcneil BJ (1985) Probabilistic sensitivity analysis using Monte Carlo simulation. A practical approach. Med Decis Making 5(2): 157-177.

28. Kingsley J, Karanth S, Revere FL, Agrawal D (2016) Cost Effectiveness of Screening Colonoscopy Depends on Adequate Bowel Preparation Rates-A Modeling Study. PLoS One 11(12): e0167452.

29. Kurlander JE, Sultan S, Saini SD (2017) The Clinical and Economic Effects of Targeted Bowel Preparation: Results of a Decision Analysis. J Clin Gastroenterol.

30. Huynh L, Yermakov S, Davis M, Campbell R, Cleveland $\mathrm{M}$, et al. (2016) Cost-analysis model of colonoscopy preparation using split-dose reduced-volume oral sulfate solution (OSS) and polyethylene glycol with electrolytes solution (PEG-ELS). J Med Econ 19(4): 356-363.

31. Russell LB Completing costs: patients' time. Med Care 47(7): 89-93.

32. Jonas DE, Russell LB, Sandler RS, Chou J, Pignone M (2008) Value of patient time invested in the colonoscopy screening process: time requirements for colonoscopy study. Med Decis Making 28(1): 5665.

33. Jonas DE, Russell LB, Sandler RS, Chou J, Pignone M (2007) Patient time requirements for screening colonoscopy. Am J Gastroenterol 102(11): 24012410 .
34. Frew E, Wolstenholme JL, Atkin W, Whynes DK (1999) Estimating time and travel costs incurred in clinic based screening: flexible sigmoidoscopy screening for colorectal cancer. J Med Screen 6(3): 119-23.

35. Henry SG, Ness RM, Stiles RA, Shintani AK, Dittus RS (2007) A cost analysis of colonoscopy using microcosting and time-and-motion techniques. J Gen Intern Med 22(10): 1415-1421.

36. Ladabaum U, Levin Z, Mannalithara A, Brill JV, Bundorf MK (2014) Colorectal testing utilization and payments in a large cohort of commercially insured US adults. Am J Gastroenterol 109(10): 1513-1525.

37. Centers for Medicare and Medicaid Services. Inpatient prospective payment system 2015.

38. Centers for Medicare and Medicaid Services. Physician fee schedule 2015.

39. Zauber A, Lansdorp-Vogelaar I, Wilschut J, Marjolen van B, Karen MK (2007) Technology assessment: cost-effectiveness of DNA stool testing to screen for colorectal cancer. Report to AHRQ and CMS from the Cancer Intervention and Surveillance Modeling Network (CISNET) for MISCAN and Sim CRC Model.

40. Data from US Dept of Labor: Bureau on Labor Statistics.

41. Information available at https://www.irs.gov/uac/newsroom/2016standard-mileage-rates-for-business-medical-andmoving-announced.

42. Van hees F, Habbema JD, Meester RG, Lansdorpvogelaar I, Van ballegooijen M, et al. (2014) Should colorectal cancer screening be considered in elderly persons without previous screening? A costeffectiveness analysis. Ann Intern Med 160(11): 750759.

43. Law R, Das A, Gregory D, Komanduri S, Muthusamy R, et al. (2016) Endoscopic resection is cost-effective compared with laparoscopic resection in the management of complex colon polyps: an economic analysis. Gastrointest Endosc 83(6): 1248-1257.

44. Ladabaum U, Mannalithara A, Jandorf L, Itzkowitz SH (2015) Cost-effectiveness of patient navigation to increase adherence with screening colonoscopy 


\section{Gastroenterology \& Hepatology International Journal}

among minority individuals. Cancer 121(7): 10881097.

45. Ramsey SD, Andersen MR, Etzioni R, Moinpour C, Peacock S, et al. (2000) Quality of life in survivors of colorectal carcinoma. Cancer 88(6): 1294-1303.

46. Hassan C, Bretthauer M, Kaminski MF, Polkowski M, Rembacken B, et al. (2013) Bowel preparation for colonoscopy: European Society of Gastrointestinal Endoscopy (ESGE) guideline. Endoscopy 45(2): 142150.

47. Hong SN, Sung IK, Kim JH, Choe WH, Kim BK, et al. (2012) The Effect of the Bowel Preparation Status on the Risk of Missing Polyp and Adenoma during Screening Colonoscopy: A Tandem Colonoscopic Study. Clin Endosc 45(4): 404-411.

48. Clark BT, Rustagi T, Laine L (2014) What level of bowel prep quality requires early repeat colonoscopy: systematic review and meta-analysis of the impact of preparation quality on adenoma detection rate. Am J Gastroenterol 109(11): 17141724.

49. Gagneja HK, Parekh P, Burleson D, Johnson D (2016) HyGleaCare ${ }^{\circledR}$ Preparation for Colonoscopy-A Technical Update for Success. J Gastrointest Dig Syst 6: 458 .

50. Heitman SJ, Hilsden RJ, Au F, Dowden S, Manns BJ (2010) Colorectal cancer screening for average-risk North Americans: an economic evaluation. PLoS Med 7(11): e1000370.

51. Heitman SJ, Ronksley PE, Hilsden RJ, Manns BJ, Rostom A, et al. (2009) Prevalence of adenomas and colorectal cancer in average risk individuals: a systematic review and meta-analysis. Clin Gastroenterol Hepatol 7(12): 1272-1278.

52. Van rijn JC, Reitsma JB, Stoker J, Bossuyt PM, Van deventer SJ, et al. (2006) Polyp miss rate determined by tandem colonoscopy: a systematic review. Am J Gastroenterol 101(2): 343-350.

53. Pickhardt PJ, Choi JR, Hwang I, Butler JA, Puckett ML, et al. (2003) Computed tomographic virtual colonoscopy to screen for colorectal neoplasia in asymptomatic adults. N Engl J Med 349(23): 21912200.
54. Lin JS, Piper MA, Perdue LA, Rutter CM, Webber EM, et al. (2016) Screening for Colorectal Cancer: Updated Evidence Report and Systematic Review for the US Preventive Services Task Force. JAMA 315(23): 25762594.

55. Reumkens A, Rondagh EJ, Bakker CM, Winkens B, Masclee AA, et al. (2016) Post-Colonoscopy Complications: A Systematic Review, Time Trends, and Meta-Analysis of Population-Based Studies. Am J Gastroenterol 111(8): 1092-1101.

56. Laiyemo AO, Murphy G, Albert PS, Sansbury LB, Wang $\mathrm{Z}$, et al (2008) Postpolypectomy colonoscopy surveillance guidelines: predictive accuracy for advanced adenoma at 4 years. Ann Intern Med 148(6): 419-426.

57. Vatn MH, Stalsberg H (1982) The prevalence of polyps of the large intestine in Oslo: an autopsy study. Cancer 49(4): 819-825.

58. Williams AR, Balasooriya BA, Day DW (1982) Polyps and cancer of the large bowel: a necropsy study in Liverpool. Gut 23(10): 835-842.

59. Clark JC, Collan Y, Eide TJ, Estève J, Ewen S, et al. (1985) Prevalence of polyps in an autopsy series from areas with varying incidence of large-bowel cancer. Int J Cancer 36(2): 179-186.

60. Winawer SJ, Zauber AG, Fletcher RH, Stillman JS, O'brien MJ, et al. (2006) Guidelines for colonoscopy surveillance after polypectomy: a consensus update by the US Multi-Society Task Force on Colorectal Cancer and the American Cancer Society. CA Cancer J Clin 56(3): 143-159.

61. Cronin KA, Ries LA, Edwards BK (2014) The Surveillance, Epidemiology, and End Results (SEER) Program of the National Cancer Institute. Cancer 120(23): 3755-3757.

62. NIH. SEER Fast Stats. seer.cancer.gov/faststats: National Cancer Institute, 2016.

63. O'connell JB, Maggard MA, Ko CY (2004) Colon cancer survival rates with the new American Joint Committee on Cancer sixth edition staging. J Natl Cancer Inst 96(19): 1420-1425.

64. Hardcastle JD, Chamberlain JO, Robinson MH, Moss SM, Amar SS, et al. (1996) Randomised controlled 


\section{Gastroenterology \& Hepatology International Journal}

trial of faecal-occult-blood screening for colorectal cancer. Lancet 348(9040): 1472-1477.

65. Kronborg O, Fenger C, Olsen J, Jørgensen OD, Søndergaard O (1996) Randomised study of screening for colorectal cancer with faecal-occultblood test. Lancet 348(9040): 1467-1471.
66. Shaukat A, Mongin SJ, Geisser MS, Lederle FA, Bond $\mathrm{JH}$, et al. (2013) Long-term mortality after screening for colorectal cancer. N Engl J Med 369(12): 11061114.

67. United States Life Tables (2011) NVSR 64(11): 63 pp (PHS) $2015 \quad-1120$ available at http://www.cdc.gov/nchs/products/life_tables.htm. 